\title{
DETERMINING THE EFFECTS OF THE COVID-19 CRISIS ON HUMAN RESOURCE MANAGEMENT IN ORGANIZATIONS
}

\author{
Ljupcho Eftimov ${ }^{1}$ \\ Tanja Kamenjarska ${ }^{2}$
}

Received: April 20, 2021 / Revised: June 29, 2021 / Accepted: July 16, 2021

(C) Association of Economists and Managers of the Balkans, 2021

\begin{abstract}
Human resource management (HRM), as a crucial constituent of crisis management, has paramount importance in managing the employees and ensuring business continuity, especially during the COVID-19 pandemic. In the constellation of such circumstances, this paper aims to identify the impact of COVID-19 on the HRM in organizations and provide recommendations for the development of long-term strategies, effective management practices and activities that are expected to result in increased employee satisfaction and retention as an organizational response to the crisis. Considering the dynamics and ever-changing environment dominantly, this paper attempts to contribute and expand the HRM literature by providing a comprehensive overview of the level of resilience of HR managers in North Macedonia to deal with a crisis such as the COVID-19 pandemic and valuable insight into the adequacy of the measures taken. As for the purpose of determining the impact of the crisis on the HRM practices, a structured questionnaire was developed and distributed to the top and middle management, HR professionals and employees in selected companies in the Republic of North Macedonia. The results revealed that adequate managerial responses to the crisis positively influence the organizational performance of the observed companies.
\end{abstract}

Keywords: COVID-19, Human resource management implications, Organizational response, Crisis management, Employee retention.

JEL Classification O15 $\cdot$ H12 $\cdot$ E24

eftimov@eccf.ukim.edu.mk

Faculty of Economics in Skopje, University "Ss. Cyril and Methodius" in Skopje, bul. Goce Delcev 9V 1000 Skopje, Republic of North Macedonia

2 Faculty of Economics in Skopje, University "Ss. Cyril and Methodius" in Skopje, bul. Goce Delcev 9V 1000 Skopje, Republic of North Macedonia 


\section{INTRODUCTION}

The COVID-19 pandemic has inevitably imposed organizations to profoundly transform their dayto-day activities and management practices and rapidly operationalize innovative workarounds of the business processes in order to withstand the unpleasant effects of the crisis which resulted in reduced salaries, labour shortage, unpleasant working conditions and employee dismissal. HR managers are viewed as a bridge between management and the staff to communicate with them, to keep positive interaction, and maintain organizational values (Gigauri, 2020). Introducing agile and flexible workforce strategies, as a response to the current market conditions, has become a major constituent in enhancing firm performance, ensuring competitive advantage and survival of the business in today's dynamic environment. In the constellation of such relations, adaptive HR practices and agile labour force planning promote trustworthy organizational culture, innovative problem-solving approaches, encourage organizational change, create synergy, and introduce smart and cost-effective use of space.

Nowadays, strategic human resource management (SHRM) highlights the growing change in the HRM function from being prescriptive, reactive and administrative to being descriptive, proactive and executive (Fahim, 2018). In this respect, HR professionals are expected to significantly contribute to the development of steadily coping mechanisms and recovery strategies in organizations. From an intraorganizational point of view, during the COVID-19 outbreak, a pivotal element is to empower employees and increase labour productivity. This is, most commonly, achieved by introducing remote working policies that include well-defined strategies concerning the positions eligible for operating remotely, availability expectations of employees, two-way communication mechanisms and cybersecurity measures especially for-profit and non-profit organizations operating with highly confidential customer data such as banks, insurance companies, educational or healthcare institutions.

Ultimately, this paper attempts to identify the relation and role of human resource management in crisis management, to provide a comprehensive analysis of the main indicators such as unemployment rates and remote working levels to determine the impact of the COVID-19 crisis on the HRM practices in selected countries, and finally to specify recommendations of HRM and organizational responses to the COVID-19 outbreak.

\section{LITERATURE OVERVIEW AND HYPOTHESES DEVELOPMENT}

The establishment of adequate working conditions accompanied by a set of formal and informal organizational configurations that prompt acknowledgment and recognition of efficient workplace actions and incentives can have a notable impact on stimulating the employee's behaviour. This is frequently achieved by the implementation of reward programs and stimulants that consist of a mix of internal rewards, such as challenging assignments, and external rewards, such as higher compensation and peer recognition (Chandrasekar, 2011).

The research conducted by Mcguire \& Mclaren (2007) revealed that the working environment not only develops interaction between the employees, collaboration and innovation within the organization but also increases job satisfaction and has a significant impact on employees' well-being. Supporting these results, Noah and Steve (2012) revealed that a working environment in an organization increases the level of job satisfaction that ultimately leads to the achievement of organization goals. Oppositely, employees that are conducting their business tasks and activities in an insecure and unhealthy environment tend to be prone to occupational diseases as a result of 
the negative influences of the environment on their performance, which affects the overall productivity of the organization (Chandrasekar, 2011). This is also supported by Sheikh Ali et al. (2013) who note that organizations that maintain the working conditions and working environment to a certain optimal threshold level tend to have increased employee performance followed by a decrease if this level is surpassed. Additionally, the compensation programs, rewards incentives, job security and working environment can increase the level of commitment and sense of belonging with the organization (Arokiasamy, 2013).

A balanced work-life is associated with increased job satisfaction and organizational commitment. Employees' work-life experiences deepen their role-related engagement which is related to organizational performance improvement (Nanzushi, 2015). In that context, numerous conducted researches have stressed the important role of work-life balance as it is related to employees' psychological well-being and overall sense of harmony in life (Clark, 2000). In the study conducted by Porathe (2009), it has been found that adequate knowledge and understanding of employees' behaviour is the crucial factor that embodies individual performance and it has a significant impact on the overall organizational performance. To do so, managers are encouraged to include employees to participate in the decision-making process which can result in the formation of the working environment.

Extensive employee participation in management style has a critical role for cross-functional addition and efficient working (Masood, 2010). As noted by Tan and Nasurdin (2012), innovative firms include HRM practices as part of the organization's strategy that encourages team working which results in enhanced customer relationships and retention through participation. In that manner, the employees, as a crucial and most valuable asset in organizations, should be nurtured generously and the retention and acquirement of new talent should be the main focus for the HR professionals (Mishra, 2010). Additionally, Lings (2004) suggest that the internal marketing orientation has implications not only for internal aspects of organizational performance, such as employee's retention, their motivation, satisfaction and organizational commitment, but also for external aspects of performance such as service quality, client satisfaction and, in the end, financial performance. Finally, the employees tend to seek those employment opportunities that are ready to invest in their personal growth (Schweitzer \& Lyons, 2008). In the constellation of such circumstances, we propose the following hypotheses:

H1a: Firm environment has a statistically significant effect on employee performance.

H1b: Firm environment has a statistically significant effect on employee behaviour.

H1c: Firm environment has a statistically significant effect on the job-related factors.

H2a: The job-related factors have a statistically significant effect on employee performance.

H2b: Employee behaviour has a statistically significant effect on employee performance.

H3: Employee performance has a statistically significant effect on organizational performance.

Figure 1 presents the conceptual framework and demonstrates the proposed networked relations between the variables. In addition, it compiles and systematizes the basic concepts for the development of the proposed evaluation model. 


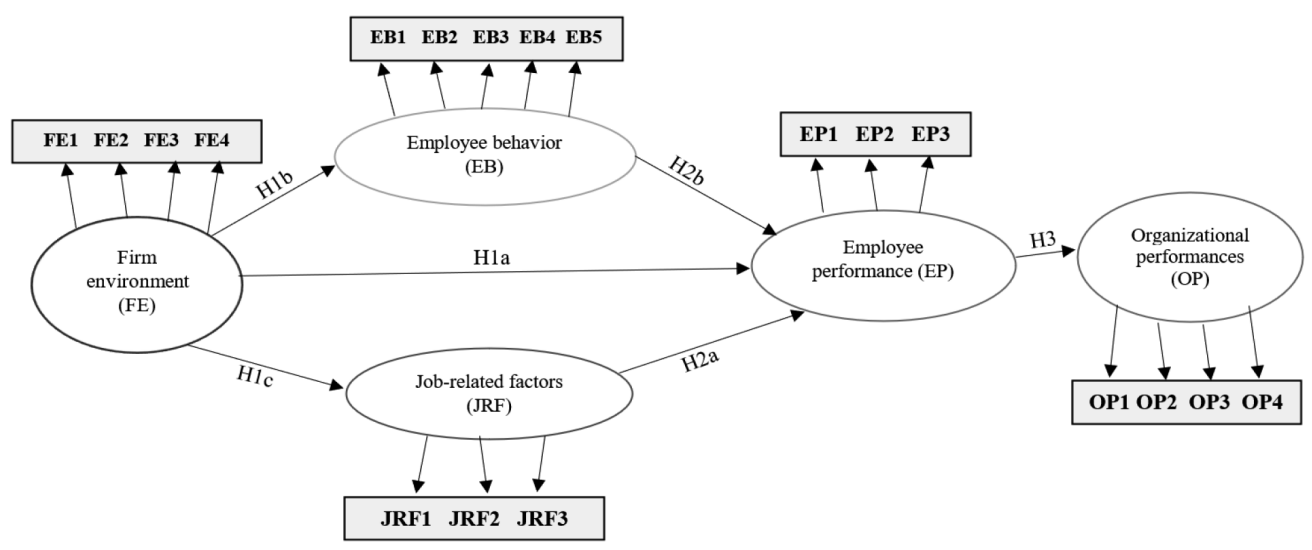

Figure 1. Conceptual framework and hypothesis development

Source: Author's elaboration

\section{DATA AND METHODOLOGY}

In order to empirically investigate what are the main effects of the COVID-19 on the HRM in organizations in the Republic of North Macedonia, primary data sources were used, which were obtained through a structured questionnaire, that was distributed over three weeks with the help of field assistants and associates to the top and middle management, HR professionals and employees in the companies with long experience in the sector who have a solid knowledge of current and previous organizational practices in various functional areas and HRM practices.

Efforts were made to explain the importance of the research to each respondent and thus to encourage the respondents to be truthful and faithful in their answers, all in order to preserve the objectivity and reliability of the research. The questionnaires sent to the respondents contained a brief explanation stating the purpose of the research, the importance of the respondents' participation, a statement guaranteeing the confidentiality of the answers and gratitude.

The questionnaire was self-administered as this type of questionnaire is easy to distribute, it is economical, and it included 25 questions. The questionnaire was developed in direction of the proposed employee evaluation model by Diamantidis \& Chatzoglu (2018) and modified by the specific needs for determining the effects of the COVID-19 on the HRM. It is divided into five parts which include perceptual assessment of the respondents for each construction in the conceptual model.

After adopting a suitable technique for data collection and passing the screening and cleaning process, a sample of 74 respondents was collected. The research sample was randomly selected from large and medium enterprises that conduct their business activities in the Republic of North Macedonia. The questions were short, concise and clear, and respondents were asked to rate the HRM activities that were available and implemented in their companies in the last 6-12 months on a Likert scale from 1 to 5 ( 1 = ,low success” $2=$,,partially successful”, $3=$,neutral”, 4 = ,, successful”, 5 = „very successful”).

The questions were developed after a detailed review of the literature related to the HRM practices and organizational performance in the companies, and the measures for each item were designed and based on theoretical and operational definitions and aspects in the literature. The collected 
data were coded and reviewed in order to eliminate any deviations or any other variations in the data set. The answers were analysed using the statistical software IBM SPSS 23, Stata and IBM SPSS AMOS 24. To conduct the empirical research, we apply a Structural Equation Model to validate the conceptual model based on KMO measure, Cronbach's alpha test, convergent validity analysis, EFA analysis, CFA analysis and SEM analysis.

\section{RESULTS AND DISCUSSION}

The validity of the constructs was measured using the Bartlett sphericity test and the Kaiser-Mayer-Olkin measure (KMO) for sampling adequacy of individual variables (Rajapathirana \& Hui, 2018). The total score of KMO is considered valid with a value of 0.6 or more to conduct factor analysis (Özdamar, 2017). The results of the Bartlett and KMO sphericity test (0.700) found that the data set was suitable for factor analysis (Table 1). The explained cumulative variance is $77.359 \%$, which exceeds the acceptable limit of $60 \%$ (Özdamar, 2017). Bartlett's sphericity test indicates a sufficient correlation between the variables with a value of 740.582 and it is significant for $\mathrm{p}<0.001$. The obtained values show that the scales used in the research are valid.

Table 1. KMO and Bartlett's test

KMO Bartlett's test

\begin{tabular}{lc}
\hline Kaiser-Mayer-Olkin (KMO) measures of sampling adequacy & 0.700 \\
\hline Bartlett's Test of Sphericity & \\
\hline Approx. chi-square & 740.582 \\
\hline Df & 300 \\
\hline Sig. & 0.000 \\
\hline
\end{tabular}

Source: Author's calculation

The factor loading on each scale exceeds 0.5 (Ringle et al., 2015) and thus these values indicate that the measurements have an acceptable convergent validity. Furthermore, reliability measures were assessed by factor loadings of items having an acceptable value of 0.70 and a Cronbach $\alpha$ value of 0.7 or more (Ringle et al., 2015).

The reliability coefficient was tested using Cronbach $\alpha$ in order to measure the reliability of a set of two or more structures. According to the test results, the total reliability scales for the factors range from 0.568 to 0.895 (Table 2) and exceed the 0.7 thresholds introduced by Nunnally (1978). Construct reliability (composite reliability - CR) and average variance extracted (AVE) were used as convergent validity measures (Fornell \& Larcker, 1981). Convergent validity was achieved because the values of AVE and CR are higher than the minimum thresholds of 0.50 and 0.70 (Fornell \& Larcker, 1981; Ringle et al., 2015).

Some authors note that CR must reach a value of 0.6 or more (Fornell \& Larcker, 1981). The results also showed that all latent variables reached the reference value of 0.7 (Nunnally \& Bernstein, 1994) (Table 2). Regarding AVE, all constructions exceed the proposed value of 0.5 (Bagozzi \& Yi, 1988), i.e. they range from 0.561 to 0.637 , which indicates that the measure has adequate convergent validity. Finally, the measurement model showed adequate reliability, convergent and discriminatory validity.

To detect possible mediations, we could conduct more hierarchical regression analyses following the procedure developed by Baron \& Kenny (1986), but due to the complexity and multiplicity 
of mediating effects, in order to discover the best structure of complex relationships between the analysed variables, the implementation of the SEM approach is preferred. Hence, a one-step SEM analysis was performed, with simultaneous assessment of the measurement and structural models in IBM SPSS AMOS 24.

Table 2. Degree of internal consistency and convergent validity

\begin{tabular}{|c|c|c|c|c|c|}
\hline Factors & Items & Factor loads & Cronbach $\alpha$ & AVE & $\mathrm{CR}$ \\
\hline FEF & $\begin{array}{l}\text { Management support } \\
\text { Training culture } \\
\text { Organizational culture } \\
\text { Environmental dynamism } \\
\end{array}$ & $\begin{array}{l}0,792 \\
0,843 \\
0,715 \\
0,837 \\
\end{array}$ & 0,838 & 0,637 & 0,875 \\
\hline JRF & \begin{tabular}{|l|} 
Job environment \\
Job communication \\
Job autonomy \\
\end{tabular} & $\begin{array}{l}0,686 \\
0,779 \\
0,797 \\
\end{array}$ & 0,841 & 0,570 & 0,798 \\
\hline EB & \begin{tabular}{|l|} 
Proactivity \\
Adaptability \\
Motivation \\
Commitment \\
Skill level \\
\end{tabular} & $\begin{array}{l}0,632 \\
0,758 \\
0,893 \\
0,883 \\
0,685 \\
\end{array}$ & 0,817 & 0,604 & 0,882 \\
\hline EP & $\begin{array}{l}\text { Achieved results } \\
\text { Satisfaction of the performance } \\
\text { Task performance during crisis } \\
\end{array}$ & $\begin{array}{l}0,761 \\
0,895 \\
0,719 \\
\end{array}$ & 0,715 & 0,632 & 0,836 \\
\hline OP & \begin{tabular}{|l|} 
Financial performance \\
Internal business processes \\
Relation company-customer \\
Knowledge and growth \\
\end{tabular} & $\begin{array}{l}0,828 \\
0,831 \\
0,741 \\
0,568 \\
\end{array}$ & 0,800 & 0,561 & 0,834 \\
\hline
\end{tabular}

Source: Author's calculation

The results consistently support the factor structure for all factors. The structured model of SEM investigates the impacts of different types of HR-related measures on the organizational performances in the companies in the COVID-19 period and proposes a theoretical scheme for such a network of relationships as presented in Figure 1, which is also a conceptual framework of the research. As a result, the proposed relationship paths that correspond to the types of HR-related measures towards the employee performance of the firm and consequently the organizational performance are analysed.

The structured model is also supported by appropriateness indices (Table 3). Adequacy indices include the Comparative Fit Index (CFI; Bentler, 1990), the Normative Fit Index (NFI; BentlerBonett, 1980), the Relative Fit Index (RFI; Bollen, 1986), the Increase Fit Index (IFI; Bollen, 1989b) and the Tucker-Lewis index (TLI; Bentler \& Bonett, 1980). All of these indices indicate a very good fit when close to 1 . Brown \& Kadek (1993) found that a value of about 0.08 or less for the Root Mean Square Error Approximation (RMSEA) would indicate a reasonable approximation error. On the other hand, Hu \& Bentler (1999) suggest that, for continuous data, RMSEA $<0.08$, TLI $<0.95$, CFI $<0.95$ are necessary values for model fit. The comparative fit index (CFI) exceeded the recommended breakout level of 0.9 (Bagozzi \& Yi, 1988). The root means square approximation error (RMSEA) is in line with the cross-sectional level of 0.08 recommended by Brown \& Kadek (1993). The combination of these results suggested that the measurement model showed a good level of suitability. These indices are shown in Table 3 and they showed a moderate but acceptable level of overall model adequacy and therefore provided support for the overall validity of the structural model. 
Table 3. Goodness-of-fit indices

\begin{tabular}{|l|c|c|}
\hline Goodness-of-fit indices & Construct & Reference value \\
\hline Chi2/degree of freedom & 1,764 & $1<\chi 2 / \mathrm{df}<5$ \\
\hline CFI (comparative fit index) & 0,967 & $0,95<\mathrm{CFI}<1$ \\
\hline NFI (normed fit index) & 0,921 & $0,90<\mathrm{NFI}<1$ \\
\hline RFI (relative fit index) & 0,947 & $0,90<\mathrm{RFI}<1$ \\
\hline IFI (incremental fit index) & 0,963 & $0,95<\mathrm{IFI}<1$ \\
\hline TLI (Tucker-Lewis fit index) & 0,964 & $0,95<\mathrm{TLI}<1$ \\
\hline RMSEA (root mean square error) & 0,074 & RMSEA $<0,08$ \\
\hline
\end{tabular}

Source: Author's calculations

From Table 4 it can be determined through standardized path estimates (SPE) that the environment in which the company operates has a positive impact on the employee behaviour $(0,52)$, job-related factors $(0,92)$, as well as a direct and positive effect on the employee performance $(0,67)$. Furthermore, the employee behaviour is found to have a positive impact on the employee performance $(0,84)$ while the job-related factors positively but insignificantly affected the employee performance $(0,24)$. Consequently, hypotheses that suggest a significant relationship between the independent variables and the organizational performance are supported and are statistically significant at $1 \%$, with exception of one hypothesis (H2a). In addition, the analysis provides interesting findings beyond the general confirmation of the hypothesized relationship. The findings reveal that the internal and external environmental firm factors directly and positively influence employee performance and result in increased organizational performance. Also, according to the regression estimates in the SEM model, it is noted that the factors related to employee behaviour are the strongest driver of organizational performance in companies in the Republic of North Macedonia. Finally, the independent sample t-test procedure is also used to investigate the likely effects of the firm environment during the COVID-19 pandemic on organizational performances. The results reveal that companies that are focused on providing a significant effort in encouraging and stimulating dedicated employee behaviour have greater employee and, consequently, organizational performances.

Table 4. Standardized path estimates and hypothesis test

\begin{tabular}{|cc|c|c|c|c|}
\hline \multicolumn{2}{|c|}{ Hypothesis } & Path & SPE & P & Result \\
\hline H1 & A & FE $\rightarrow$ EP & 0,67 & 0,000 & Accepted \\
\hline & B & FE $\rightarrow$ EB & 0,92 & 0,002 & Accepted \\
\hline \multicolumn{2}{|c|}{ C } & FE $\rightarrow$ JRF & 0,96 & 0,000 & Accepted \\
\hline H2 & A & JRF $\rightarrow$ EP & 0,24 & 0,617 & Rejected \\
\hline & B & EB $\rightarrow$ EP & 0,84 & 0,000 & Accepted \\
\hline H3 & EP $\rightarrow$ OP & 0,61 & 0,002 & Accepted \\
\hline
\end{tabular}

Source: Author's calculations

The statistically significant and positive impact of the working environment on employee performance is in line with the results obtained from a number of studies (Ollukkaran \& Gunaseelan, 2003; Leblebici, 2012; Arokiasamy, 2013). The development and implementation of long-term management support measures as a crucial constituent of the organizational strategies ought to increase job satisfaction and prompt an open organizational culture that encourages employees to share their knowledge and generate a corpus of ideas. Furthermore, the positive effect of the firm environment on the employee behaviour and the job-related factors indicates that the ability to adapt to the environmental dynamism and the establishment of a training culture within 
the organization is likely to be beneficial for the employees and result in personal growth and acquired expertise while increasing the level of commitment and sense of belonging within the organization.

In addition to these results, it can be noticed that job related factors have a positive but statistically insignificant effect on the employees' performances. These findings do not correspond to the results of theoretical and empirical research (Morrison, 2006; Grant \& Ashford, 2008; Diamantidis \& Chatzoglou, 2018), in which a positive impact of the job-related factors was observed on the employees' performance. This can be a result - that the optimal level of job autonomy has already been reached in the pre-COVID-19 period in the observed companies. Additionally, this can be explained that in a stable job environment, employees tend to be proactive, feel "free" in their workplaces and express innovative ideas while taking the initiative to solve job-related problems. The observed positive and statistically significant impact of the employee behaviour on the employee performance indicates that employees' innovative behaviours are consistently useful to improve the business practices are and considered as a significant source for the organization's competitive advantage (Anderson et al., 2014; Shin et al., 2017). This finding also suggests that the high-level commitment incorporates psychological attachment that enhances the ability to work and this improves the understanding of behaviours which leads to an improved organizational learning environment (Hussain et al., 2018).

Furthermore, the results reveal a positive and statistically significant impact of the employee performance and organizational performance which is in line with multiple studies (Tarmidi \& Arsjah, 2019) and it is suggested for the companies to pay dominant attention to developing and implementing training culture as a crucial element for reaching cohesive crisis response as the human resource capital has a prominent role in gaining a competitive advantage and ensures the continuous growth of the organization.

\section{RECOMMENDATIONS FOR HRM AND ORGANIZATIONAL RESPONSES TO THE COVID-19 CRISIS}

HRM strategies not only affect the ability of individuals to operate, to compete, and the effectiveness of the organization, but it has also been emphasized that the lack of effective communication between decision-makers and administrators is one of the most significant causes of organizations failing to control the crisis and reduce its negative impacts (Eshkavandi et al., 2015). HRM alongside the top management serves as principal protagonists in the identification of potential internal and external threats. They enable employees to adapt to complex crises such as the COVID-19, promote synergy and as a result, ensure sustainability and productivity in organizations. For that purpose, we have identified nine crucial SHRM incentives that ought to contribute to the recovery practices and organizational responses to the COVID-19 pandemic:

- Establish adequate HR protection mechanisms. Intellectual capital, if efficiently managed, can significantly contribute to the expansion of knowledge, experience, and know-how skills within the organizations, which in times of COVID-19 can be a remarkable driver in gaining competitive advantage in the market. In that manner, the HR professionals and the top management must implement proactive employee protection practices for the promotion and protection of human rights, but also increase employee crisis readiness that can result in improved organizational performance and overall, more sustainable economic growth.

- Promote organizational agility. By continuously providing effort in the development of the dynamic capabilities (speed, nimbleness, responsiveness) and agility, organizations significantly enhance the employee engagements and innovation capabilities which in times of 
crisis are critical factors to achieve and maintain competitive leadership. Analogous to that, innovative businesses tend to be less vulnerable than non-innovative companies in terms of cyclical sectoral and environmental pressures, and the ability to innovate in an ever-changing environment allows companies to improve their current business processes, launch new products and implement new technologies.

- Align HR capacities with organizational objectives during the pandemic. The culture of change can help organizations to prioritize goals and the benefits of adequate talent management practices ought to ensure business survival, especially at the time of COVID-19. Consequently, HR professionals need to keep the employees well-informed of the measures taken in the shift of the business strategies during the crisis. In that way, setting objectives and minimizing biases in communicating the strategic decisions could improve the operational performance in the organizations.

- Empower employees by nurturing positive relationships and taking safety initiatives. One of the most important constituents in any SHRM practice is the implementation of safety measures during the time of the COVID-19 crisis. HR professionals should analyse the potential safety risks of employees' work activities and provide hazard controls mechanisms. This allows companies to enhance their brand image and reputation, and also by fostering an organizational climate that takes into consideration the employee's safety will increase the social responsibility and the collective conscience. In such unpredictive times, managers ought to focus on the nurturing of understanding, supportive and trustworthy relationships with the subordinates, listen intently and encourage employees to disclose their ideas, opinions, and perceptions.

- Introduce the employees to the remote working strategies. HR professionals need to consider work and family differences when addressing this issue, as the work-family linkage is different for various types of work and distinct family structures, and hence, worklife balance requirement is also different (Edwards \& Rothbard, 2000; Mushkudiani \& Dzotsenidze, 2019). Therefore, managers are advised to communicate with remote workers frequently and to be focused on employee well-being (Meister, 2020).

- Promote workplace diversity and inclusion. By introducing an inclusive workplace culture, organizations with diverse employee structures tend to increase the brainstorming of new ideas, different perspectives and experiences. This will allow the company to develop out-of-the-box thinking which most likely can be a significant factor in ensuring business sustainability in crisis situations.

- Demonstrate personal instead of positional power. During the COVID-19 outbreak, the top management and HR professionals faced the challenge of influencing employees to adapt to the imposed dynamic changes. The inherent positional power as a type of authority managers practice appears to have less impact when motivating the employees in remote-friendly environments than the executed power derived from the expertise, knowledge, interpersonal relationships, or personality of the superiors. In times of the COVID-19 pandemic, the importance of demonstrating empathy and taking into consideration the fundamental human needs are critical success factors in organizations.

- Organize efficient training programs and increase crisis readiness. In the process of searching and reaching optimal levels of crisis readiness, the organization should most importantly, designate crisis response team members and provide efficient crisis leadership. To do so, HR professionals are advised to maximize the use of the technological benefits when organizing training programs and workshops while attempting to enhance and achieve efficiencies in the optimization of crisis readiness.

- Reward employee engagement. The implementation of recognition-based incentives can result in the enhanced accomplishment of business tasks, increased creativity and inno- 
vativeness of employees. In cases of crisis situations, the HR managers should dominantly focus on providing rewards in form of opportunities for professional development and growth, public acknowledgment and recognition or encouraging employees to pursue their ideas. This can further increase the employee commitment and overall operational performance of the organizations.

\section{CONCLUSION}

This paper contributed to the literature as pioneering research which enhanced the understanding of the effects that the COVID-19 pandemic has left on the HRM practices. The findings support the claim that some of the HRM practices that were implemented in companies during the COVID-19 crisis have a significant impact on organizational performances. These findings support our conceptual model and offer several managerial implications.

The top management, as well as the HR professionals, need to place additional emphasis on finding and implementing optimal work-life balance mechanisms, especially during the times of COVID-19 as they are important tools for achieving sustainable competitive power and market leadership.

Improved organizational performance depends on the degree of implementation of adequate HRM measures. Firms that have the resources and knowledge to improve their HRM capabilities could expect a significant improvement in the sales and market performance if they encourage and implement an appropriately balanced level of HRM activities. Furthermore, the research model should be further developed and analysed with samples from other countries since the cultural differences between organizations differ significantly and affect the perception of employees in terms of knowledge sharing, and in that context, further theoretical and empirical research will provide stronger verification of the results obtained from this study.

\section{REFERENCES}

Anderson, N., Potočnik, K., \& Zhou, J. (2014). Innovation and creativity in organizations a stateof-the-science review, prospective commentary, and guiding framework, Journal of Management, 40, 1297-1333.

Arokiasamy, A. R. A. (2013). A study on employee satisfaction perspectives in the hotel industry in Malaysia, International Journal of Management and Strategy, 4(6).

Arokiasamy, A.R.A (2013). A qualitative study on causes and effects of employee turnover in the private sector in Malaysia, Middle East Journal of Scientific Research, 16(11), 1532-1541.

Bagozzi, R.P. \& Yi, Y. (1988). On the evaluation of structural equation models, JAMS, 87 (16), 74-94.

Baron, R. M., \& Kenny, D. A. (1986). The moderator-mediator variable distinction in social psychological research: Conceptual, strategic, and statistical considerations, Journal of Personality and Social Psychology, 51 (6), 1173- 1182.

Bentler, P. M. (1990). Comparative fit indexes in structural models, Psychological Bulletin, 107(2), 238-246

Bentler, P. M., \& Bonett, D. G. (1980). Significance tests and goodness of fit in the analysis of covariance structures, Psychological Bulletin, 88 (3), 588-60.

Chandrasekar K. (2011). Workplace Environment and its Impact on Organizational Performance in Public Sector Organizations, International Journal of Enterprise Computing and Business Systems, 1(1). 
Clark, S.C. (2000). Work/family border theory: A new theory of work/family balance, Human Relations, 53 (6), 747-770.

Diamantidis, A.D. \& Chatzoglou, P.D. (2018). Factors affecting employee performance: an empirical approach, International Journal of Productivity and Performance Management 68(1).

Edwards, J. R., \& Rothbard, N. P. (2000). Mechanisms linking work and family: Clarifying the relationship between work and family constructs, Academy of Management Review, 25(1), 178-199.

Eshkavandi, A. M., Dolatabadi, R. H., \& Tabatabaei, N. S. (2015). Identifying and prioritizing the components of strategic foresight capabilities, crisis management and human resource agility in the blood transfusion organization using Delphi method and AHP, Journal of management futures research, 26(102), 55-68.

Fahim, M.G.A. (2018). Strategic human resource management and public employee retention, Review of Economics and Political Science, 3(2), 20-39.

Fornell, C. \& Larcker D.F. (1981). Evaluating Structural Equation Models with Unobservable Variables and Measurement Error, Journal of Marketing Research, Published by: Sage Publications, Inc., 18 (1), 39-50.

Gigauri, I. (2020). Effects of Covid-19 on Human Resource Management from the Perspective of Digitalization and Work-life-balance, International Journal of Innovative Technologies in Economy, 4(31)

Grant, A.M. \& Ashford, S.J. (2008). "The dynamics of proactivity at work", Research in Organizational Behavior, 28, 3-34.

Hu, L. T., \& Bentler, P. M. (1999). Cutoff Criteria for Fit Indexes in Covariance Structure Analysis: Conventional Criteria versus New Alternatives. Structural Equation Modeling, 6, 1-55.

Hussain, I., Nazir, S., Shaheen, I., Waseem, A., Shafiq, M. (2018). Impact of Employees' Behavior on Organizational Learning: Moderating Role of Knowledge Management, International Journal of Business and Social Science, 9 (3).

Leblebici, D. (2012). Impact of Workplace Quality on Employee's Productivity: Case study of A bank in Turkey, Journal of Business, Economics and Finance, 1(1), 38-49.

Lings, I. N. (2004). Internal market orientation. Construct and consequences, Journal of Business Research, 57, 408.

Masood, T. (2010). Impact of Human Resource Management (HRM) Practices on Organizational Performance: A Mediating Role of Employee Performance (Doctoral dissertation, MOHAMMAD ALI JINNAH UNIVERSITY).

McGuire, D. \& McLaren, L. (2007). The Impact of Physical Environment on Employee Commitment in Call Centres: The Mediating Role of Employee Well-Being, Team Performance Management, 14 (5/6).

Meister, J. (2020). "The Impact of The Coronavirus On HR And The New Normal Of Work."

Mishra, S. (2010). Internal Marketing - a tool to harness employees' power in service organizations in India, International Journal of Business and Management, 5 (1), 190.

Morrison, E.W. (2006). Doing the job well: an investigation of pro-social rule breaking, Journal of Management, 32(1), 5-28.

Mushkudiani, Z., \& Dzotsenidze, T. (2019). Modern Human Resource Management Trends. 5th International Scientific Conference „Modern Maritime Technologies, Problems of Social-Economic Development and Ways for solving them", (pp. 160-165). Batumi, Georgia.

Nanzushi C. (2015). The effect of workplace environment on employee performance in the mobile telecommunication firms in Nairobi city country.

Noah, Y. and M. Steve (2012). Work Environment and Job Attitude among Employees in a Nigerian Work Organization, Journal of Sustainable Society, 1(2), 36-43.

Nunnally, J. C. (1978). Psychometric theory, 2nd edition, New York: McGraw Hill. 
Ollukkaran B.A. \& Gunaseelan R. (2012). A study on the impact of work environment on employee performance. Namex International Journal of Management Research, 2(2).

Özdamar, K. (2017). Scale and test development Structural equation modeling IBM SPSS, IBM SPSS AMOS and MINTAB applied, Nisan Kitabevi.

Porathe, P., Christine, (2009). How Toxic Colleagues Corrode Performance. Harvard Business Review, 87(04).

Rajapathirana J. R.P., \& Hui Y. (2018). Relationship between innovation capability, innovation type, and firm performance, Journal of Innovation \& Knowledge, 3 (1), 44-55.

Ringle, C.M., Wende, S. \& Becker, J.M. (2015), SmartPLS GmbH, Boenningstedt.

Schweitzer, L. \& Lyons, S. (2008). The market within: A marketing approach to creating and developing high-value employment relationships, Business Horizons, 51, 562- 564.

Sheikh Ali, Abdi Ali \& Ali Adan (2013). Working conditions and employees' productivity in manufacturing companies in Sub-Saharan African context: Case of Somalia, International Journal of Educational Research, 2(2), 67-78.

Shin, S. J., Yuan, F., \& Zhou, J. (2017). When perceived innovation job requirement increases employee innovative behavior: A sensemaking perspective, Journal of Organizational Behaviour, 38, 68-86.

Tan, C. L., \& Nasurdin, A. M. (2011). Human resource management practices and organizational innovation: assessing the mediating role of knowledge management effectiveness, Electronic Journal of Knowledge Management, 9(2), 155-167.

Tarmidi D., \& Arsjah R.J. (2019). Employee and Organizational Performance: Impact of Employee Internal and External Factors, Journal of Resource Development and Management, Vol 57. 